Xiaowei Yan, Dongjian Zhu, Xing Zhong and Sujuan Wang*

\title{
Crystal structure of bis( $\eta^{6}$-cymene)-tri- $\mu_{2^{-}}$ chlorido-ruthenium(II) tetrafluoroborate, $\mathrm{C}_{20} \mathrm{H}_{28} \mathrm{BCl}_{3} \mathrm{~F}_{4} \mathrm{Ru}_{2}$
}

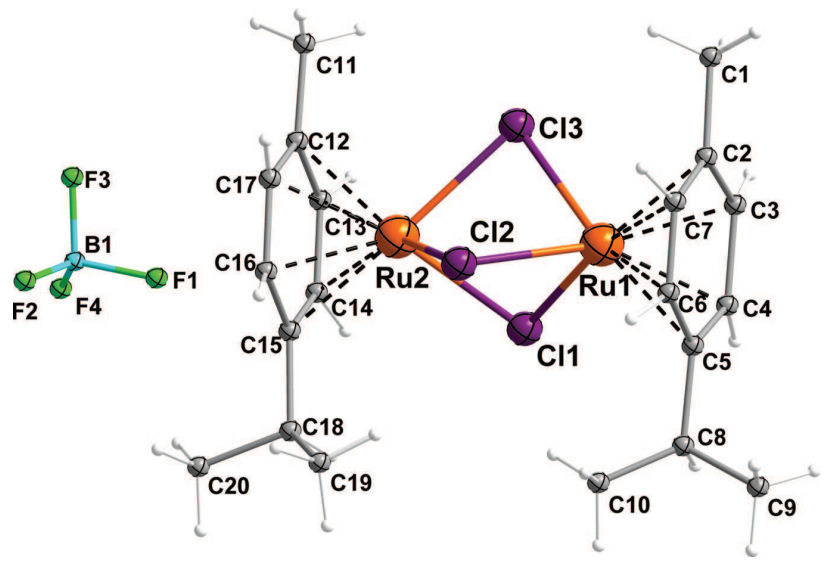

https://doi.org/10.1515/ncrs-2018-0050

Received March 1, 2018; accepted June 6, 2018; available online June 20, 2018

\section{Abstract \\ $\mathrm{C}_{20} \mathrm{H}_{28} \mathrm{BCl}_{3} \mathrm{~F}_{4} \mathrm{Ru}_{2}$, triclinic, $P \overline{1}$ (no. 2), $a=7.7061$ (15) $\AA$, $b=12.654(3) \AA, c=13.993(3) \AA, \alpha=68.25(3)^{\circ}, \beta=78.71(3)^{\circ}$, $\gamma=88.89(3)^{\circ}, \quad V=1240.8(5) \AA^{3}, \quad Z=2, \quad R_{\mathrm{gt}}(F)=0.0686$, $w R_{\text {ref }}\left(F^{2}\right)=0.2017, T=293(2) \mathrm{K}$.}

\section{CCDC no.: 1847586}

The title crystal structure is shown using a ball-and-stick scheme in the figure. Tables 1 and 2 contain details of the measurement method and a list of the atoms including atomic coordinates and displacement parameters.

*Corresponding author: Sujuan Wang, College of Food and Bioengineering, Hezhou University, No. 18 West Ring Road, Hezhou, Guangxi 542899, P.R. China, e-mail: 710831069@qq.com Xiaowei Yan and Xing Zhong: College of Materials and Environmental Engineering, and Guangxi Key Laboratory of Calcium Carbonate Resources Comprehensive Utilization, Hezhou University, No. 18 West Ring Road, Hezhou, Guangxi 542800, P.R. China

Dongjian Zhu: College of Food and Bioengineering, Hezhou University, No. 18 West Ring Road, Hezhou, Guangxi 542899, P.R. China
Table 1: Data collection and handling.

\begin{tabular}{ll}
\hline Crystal: & Prism, brown \\
Size: & $0.37 \times 0.29 \times 0.25 \mathrm{~mm}$ \\
Wavelength: & Mo $K \alpha$ radiation $(0.71073 \AA$ A $)$ \\
$\mu:$ & $1.58 \mathrm{~mm}^{-1}$ \\
Diffractometer, scan mode: & Bruker APEX, $\varphi$ and $\omega$-scans \\
$\theta_{\text {max }}$, completeness: & $27^{\circ},>99 \%$ \\
$N\left(h k l_{\text {measured }}, N(h k l)_{\text {unique }}, R_{\text {int }}:\right.$ & $12865,5645,0.043$ \\
Criterion for $I_{\text {obs }}, N(h k l)_{\mathrm{gt}}:$ & $I_{\text {obs }}>2 \sigma\left(I_{\text {obs }}\right), 4085$ \\
$N(\text { param })_{\text {refined }}:$ & 277 \\
Programs: & Bruker programs [1], SHELX [2], \\
& Diamond [3] \\
\hline
\end{tabular}

Table 2: Fractional atomic coordinates and isotropic or equivalent isotropic displacement parameters $\left(\AA^{2}\right)$.

\begin{tabular}{lrrrr}
\hline Atom & $\boldsymbol{x}$ & $\boldsymbol{y}$ & $\boldsymbol{Z}$ & $\boldsymbol{U}_{\text {iso }} \boldsymbol{U}_{\text {eq }}$ \\
\hline Ru1 & $0.63390(9)$ & $0.83339(5)$ & $0.32977(5)$ & $0.0493(2)$ \\
Ru2 & $0.87897(8)$ & $0.73838(5)$ & $0.16257(4)$ & $0.0431(2)$ \\
F1 & $0.6329(17)$ & $0.7830(12)$ & $0.8392(8)$ & $0.190(4)$ \\
F2 & $0.653(2)$ & $0.7577(13)$ & $0.7077(11)$ & $0.210(4)$ \\
F3 & $0.838(2)$ & $0.8518(15)$ & $0.6974(15)$ & $0.257(6)$ \\
F4 & $0.8349(18)$ & $0.6733(11)$ & $0.8029(9)$ & $0.186(4)$ \\
Cl1 & $0.7510(3)$ & $0.64761(17)$ & $0.34953(16)$ & $0.0607(5)$ \\
Cl2 & $0.5924(3)$ & $0.8222(2)$ & $0.16694(16)$ & $0.0591(5)$ \\
Cl3 & $0.9368(3)$ & $0.88996(18)$ & $0.22385(16)$ & $0.0566(5)$ \\
B1 & $0.754(5)$ & $0.754(3)$ & $0.778(3)$ & $0.185(6)$ \\
C1 & $0.733(2)$ & $1.0912(15)$ & $0.3235(15)$ & $0.154(7)$ \\
H1A & 0.8424 & 1.0729 & 0.3477 & $0.231^{*}$ \\
H1B & 0.6796 & 1.1493 & 0.3460 & $0.231^{*}$ \\
H1C & 0.7569 & 1.1181 & 0.2481 & $0.231^{*}$ \\
C2 & $0.6072(17)$ & $0.9843(9)$ & $0.3691(10)$ & $0.085(4)$ \\
C3 & $0.6457(16)$ & $0.8903(12)$ & $0.4554(9)$ & $0.088(3)$ \\
H3 & 0.7555 & 0.8899 & 0.4809 & $0.105^{*}$ \\
C4 & $0.5262(16)$ & $0.7870(10)$ & $0.4931(6)$ & $0.079(3)$ \\
H4 & 0.5600 & 0.7159 & 0.5430 & $0.095^{*}$ \\
C5 & $0.3829(12)$ & $0.7828(8)$ & $0.4426(7)$ & $0.062(2)$ \\
C6 & $0.3626(15)$ & $0.8780(11)$ & $0.3619(8)$ & $0.082(3)$ \\
H6 & 0.2845 & 0.8727 & 0.3161 & $0.098^{*}$ \\
C7 & $0.4727(17)$ & $0.9746(10)$ & $0.3281(10)$ & $0.086(3)$ \\
H7 & 0.4676 & 1.0326 & 0.2591 & $0.104^{*}$ \\
C8 & $0.2688(18)$ & $0.6694(12)$ & $0.4850(11)$ & $0.100(4)$ \\
H8 & 0.3289 & 0.6115 & 0.5340 & $0.120^{*}$ \\
& & & &
\end{tabular}


Table 2 (continued)

\begin{tabular}{lrrrr}
\hline Atom & $\boldsymbol{x}$ & $\boldsymbol{y}$ & $\boldsymbol{Z}$ & $\boldsymbol{U}_{\text {iso }}{ }^{*} \boldsymbol{U}_{\text {eq }}$ \\
\hline C9 & $0.0927(19)$ & $0.6877(15)$ & $0.5479(12)$ & $0.134(6)$ \\
H9A & 0.0288 & 0.7421 & 0.5012 & $0.201^{*}$ \\
H9B & 0.1152 & 0.7157 & 0.5996 & $0.201^{*}$ \\
H9C & 0.0234 & 0.6167 & 0.5823 & $0.201^{*}$ \\
C10 & $0.2405(17)$ & $0.6271(11)$ & $0.4076(10)$ & $0.097(4)$ \\
H10A & 0.1641 & 0.6757 & 0.3657 & $0.146^{*}$ \\
H10B & 0.1861 & 0.5512 & 0.4417 & $0.146^{*}$ \\
H10C & 0.3520 & 0.6258 & 0.3633 & $0.146^{*}$ \\
C11 & $1.2548(14)$ & $0.8827(10)$ & $0.0064(9)$ & $0.084(3)$ \\
H11A & 1.3585 & 0.8714 & -0.0386 & $0.127^{*}$ \\
H11B & 1.2872 & 0.8894 & 0.0668 & $0.127^{*}$ \\
H11C & 1.2025 & 0.9512 & -0.0313 & $0.127^{*}$ \\
C12 & $1.1220(10)$ & $0.7818(8)$ & $0.0415(6)$ & $0.055(2)$ \\
C13 & $1.1419(11)$ & $0.6813(8)$ & $0.1245(7)$ & $0.060(2)$ \\
H13 & 1.2289 & 0.6810 & 0.1672 & $0.072^{*}$ \\
C14 & $1.0157(14)$ & $0.5893(8)$ & $0.1598(7)$ & $0.067(2)$ \\
H14 & 1.0180 & 0.5273 & 0.2270 & $0.081^{*}$ \\
C15 & $0.8661(12)$ & $0.5936(8)$ & $0.1147(8)$ & $0.062(2)$ \\
C16 & $0.8517(12)$ & $0.6970(9)$ & $0.0303(7)$ & $0.062(2)$ \\
H16 & 0.7391 & 0.7103 & 0.0063 & $0.074^{*}$ \\
C17 & $0.9771(12)$ & $0.7888(8)$ & $-0.0044(6)$ & $0.060(2)$ \\
H17 & 0.9491 & 0.8634 & -0.0517 & $0.071^{*}$ \\
C18 & $0.7286(14)$ & $0.4964(10)$ & $0.1569(11)$ & $0.089(4)$ \\
H18 & 0.7380 & 0.4521 & 0.2296 & $0.106^{*}$ \\
C19 & $0.546(2)$ & $0.5285(13)$ & $0.1587(15)$ & $0.137(6)$ \\
H19A & 0.5219 & 0.5809 & 0.1940 & $0.206^{*}$ \\
H19B & 0.4673 & 0.4617 & 0.1952 & $0.206^{*}$ \\
H19C & 0.5281 & 0.5641 & 0.0879 & $0.206^{*}$ \\
C20 & $0.7728(19)$ & $0.4199(11)$ & $0.0962(13)$ & $0.118(5)$ \\
H20A & 0.7025 & 0.3494 & 0.1321 & $0.178^{*}$ \\
H20B & 0.8962 & 0.4048 & 0.0906 & $0.178^{*}$ \\
H20 & 0.7480 & 0.4565 & 0.0272 & $0.178^{*}$ \\
H1 & & &
\end{tabular}

\section{Source of materials}

To a solution containing $\left[\left(\eta^{6}\right.\right.$-p-cymene $\left.) \mathrm{RuCl}_{2}\right]$ in $\mathrm{CH}_{3} \mathrm{OH}$ and $\mathrm{CH}_{2} \mathrm{Cl}_{2}$, excessive $\mathrm{NaBF}_{4}$ and moderate dilute hydrochloric acid were added successively. The reaction mixture was stirred at ambient temperature for over $12 \mathrm{~h}$ and filtered to remove $\mathrm{NaCl}$. The solvents were removed from the filtrate on a rotary evaporator and the residue was recrystallized from 1:1 $\mathrm{CH}_{2} \mathrm{Cl}_{2}$ /ether to afford dark red crystals with high yield.

\section{Experimental details}

All hydrogen atoms were positioned geometrically and allowed to ride on their parent atoms.

\section{Comment}

The dinuclear triply chlorido bridged arene ruthenium(II) complexes receive widely attention $[4,5]$, because they can provide diverse coordination environments to develop metalmediated catalyst [6] and for medicinal applications [7]. Its structure was first determined nearly 40 years ago with the very large $\mathrm{BPh}_{4}{ }^{-}$as counter ion [8]. With the research going on, the tri- $\mu$-chloro-bis $\left[\left(\eta^{6} \text {-p-arene)ruthenium(II) }\right]^{+}\right.$ ion (TCRu) was observed in more and more cases [8, 10-12]. From the literature, we found the TCRu can be easily obtained by reacting the starting materials $\left[\left(\eta^{6}-p \text {-arene }\right) \operatorname{RuCl}(\mu-\mathrm{Cl})\right]_{2}$ with excessive alkali metal salts which have weakly coordinating anions, such as $\mathrm{BF}_{4}{ }^{-}$[8], $\mathrm{BPh}_{4}{ }^{-}$[9], $\mathrm{AsF}_{6}{ }^{-}$[10], $\left[\mathrm{Hg}_{2} \mathrm{Cl}_{6}\right]^{2-}[11], \mathrm{BAr}_{4}{ }^{-}(\mathrm{Ar}=\mathrm{p}$-tolyl) [12].

The title complex crystallizes in the space group $P \overline{1}$, which is different from its structural isomer which has the space group Pccn, orthorhombic [8]. The molecular structure, depicted in the figure, consists of one TCRu cation and one tetrafluoroborate anion. In the cation the $\left[\mathrm{Ru}\left(\eta^{6}-\mathrm{p}\right.\right.$-cymene $\left.)\right]$ fragments are linked by three bridging $\mathrm{Cl}$ atoms, with an average $\mathrm{Ru}-\mathrm{Cl}$ bond distance of $2.440(2) \AA$ and an average $\mathrm{Ru} 1-\mathrm{Cl}-\mathrm{Ru} 2$ bond angle of $84.4(7)^{\circ}$. Each $\mathrm{Ru}$ atom exhibits a distorted octahedral coordination with the arene ring of the p-cymene ligand formally occupying three sites. The $\mathrm{Cl}-$ $\mathrm{Ru}-\mathrm{Cl}$ angles are considerably reduced (average 79.79(7) ${ }^{\circ}$ ) because of steric interactions. The separation between two $\mathrm{Ru}$ atoms is $3.2787(13) \AA$, which agrees with the previous studies [8-11], but still beyond direct metal-metal bond [13]. The tetrahedral $\mathrm{BF}_{4}{ }^{-}$anion is ordered with average $\mathrm{B}-\mathrm{F}$ bond lengths of $1.266(2)^{\circ}$.

Apparently, the sandwich structure of the title structure between the two benzene rings of the p-cymene ligands is nearly parallel with the corresponding torsion angle about $6.42^{\circ}$, however the sandwich structure of the isomer [8] is staggered with the corresponding torsion angle about $56^{\circ}$. The influence of this configuration change led to the separation between two $\mathrm{Ru}$ atoms of the isomer getting closer than the title complex. This could be reasonably explained by the steric hindrance effect of the isopropyl group. That's the main difference between the title structure an the othorhombic analogon.

Acknowledgements: We thank the National Natural Science Foundation of China (21603064), Natural Science Foundation of Guangxi (2016GXNSFBA380002), the Middle-aged and Young Teachers' Basic Ability Promotion Project of Guangxi (2017KY0649), the Doctor's Scientific Research Foundation of Hezhou University (HZUBS201507).

\section{References}

1. Bruker. APEX3 and SAINT. Bruker AXS Inc., Madison, WI, USA (2012). 
2. Sheldrick, G. M.: A short history of SHELX. Acta Crystallogr. A64 (2008) 112-122.

3. Brandenburg, K.: DIAMOND. Visual Crystal Structure Information System. Version 3.2i. Crystal Impact, Bonn, Germany (2012).

4. Arthur, T.; Stephenson, T. A.: Synthesis of triple halidebridged arene complexes of ruthenium(II) and osmium(II). J. Organomet. Chem. 208 (1981) 369-387.

5. Bozec, H.; Daniel, T.; Dixneuf, P. H.: Organometallic chemistry of arene ruthenium and osmium complexes. In Advances in Organometallic Chemistry. Original edition, Academic Press (1989).

6. Arockiam, P. B.; Bruneau, C.; Dixneuf, P. H.: Ruthenium(II)catalyzed $\mathrm{C}-\mathrm{H}$ bond activation and functionalization. Chem. Rev. 112 (2012) 5879-5918.

7. Wu, Q.; He, J.; Mei, W.; Zhang, Z.; Wu, X.; Sun, F.: Arene ruthenium(II) complex, a potent inhibitor against proliferation, migration and invasion of breast cancer cells, reduces stress fibers, focal adhesions and invadopodia. Metallomics 6 (2014) 2204-2212.
8. Fletcher, N. C.; Horton, P. N.; Hursthouse, M. B.: University of Southampton, Crystal Structure Report Archive 1250 (2009) DOI: $10.5258 /$ ecrystals/1250.

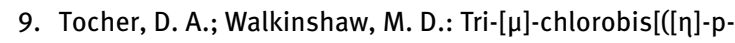
cymene)ruthenium(II)] tetraphenylborate methanol solvate. Acta Crystallogr. B38(12) (1982) 3083-3085.

10. McCormick, F. B.; Gleason, W. B.: Structure of tri$[\mu]$-chloro-bis $[([\eta] 6-$ benzene)ruthenium(II)] hexafluoroarsenate. Acta Crystallogr. Sec. C 49(8) (1993) 1493-1496.

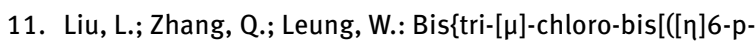
cymene)ruthenium(II)]\} di-[ $\mu$ ]-chloro-bis[dichloromercurate(II)]. Acta Crystallogr. E60 (2004) m506-m508.

12. Sumiyoshi, T.; Gunnoe, T. B.; Petersen, J. L.; Boyle, P. D.: Ruthenium(II) complexes possessing the n6p-cymene ligand. Inorg. Chim. Acta 361 (2008) 3254-3262.

13. Bennett, M. J.; Caulton, K. G.; Cotton, F. A.: Structure of tetra$n$-butyratodiruthenium chloride, a compound with a strong metal-metal bond. Inorg. Chem. 8 (1969) 1-6. 